\title{
Free operant avoidance responding as a function of serially presented variations of UCS intensity '
}

FREdericK W. HUfF, THOMAS P, PIANTANIDA AND GRANT L. MORRIS

UNIVERSITY OF SOUTH FLORIDA

Six rats were trained on a Sidman free operant avoidance task. Three UCS, shock, intensities were used, two Ss for each intensity. After training, each $S$ was presented with three different UCS intensities and differences in responding rate between one UCS intensity and another were calculated. It was observed that increasing USC intensity increased avoidance, while decreasing it decreased avoidance. Furthermore, the extent of this change in response rate was found to be a function of the prior UCS training intensity.

Levine (1966) and Bolles \& Warren (1965) found that increasing shock intensity decreased rate of avoidance responding; shock intensities ranged from .20 to $.80 \mathrm{~mA}$ in the former study and .10 to $2.2 \mathrm{~mA}$ in the latter. In two experiments conducted by Hurwitz \& Dillow (1966a, b) varying shock intensities had no effect. While Jerison (1966) obtained $80 \%$ avoidance when the UCS was $.40 \mathrm{~mA}$, it dropped to $60 \%$ when the UCS was reduced to .25 $\mathrm{mA}$. No avoidance or escape was obtained to a UCS of .20 mA or under. Since these studies varied considerably in methodology it was difficult to generalize from them. Nevertheless, the following interpretations are tentatively offered. In ac quisition a curvilinear relationship exists between shock intensity and avoidance responding. After acquisition of an avoidance response, its performance is enhanced when the UCS is higher than the training intensity, while when it is lower, performance drops off. Certainly in Jerison's study decreasing UCS intensity resulted in fewer avoidances.

The purpose of this study was to train Ss on an avoidance task and then vary the UCS intensity during performance. It was predicted that performance would increase when the UCS increased and would decrease when it was decreased. It was further thought that the amount of increase or decrease would depend on the UCS training level, but no specific hypothesis was advanced.

Subjects

Ss were six naive adult female hooded rats who had been reared in a usual laboratory environment. Apparatus

A Ralph-Gerbrands' standard operant rat cage programmed by Grason-Stadler electromechanical circuits was used. The UCS, shock, was provided by a $250 \mathrm{~V}$ ac Electro Products Laboratory Transformer, Model NFBR, and was scrambled to the grids. The bar required a pressure of $6 \mathrm{~g}$ to trip.

Procedure

Each $S$ was randomly assigned to one of three groups, two per group; both $\mathrm{Ss}$ in a group were trained on a Sidman free operant avoidance task (Sidman, 1966) at a single UCS intensity. The avoidance schedule was one in which the $S-S$ interval was $5 \mathrm{sec}$ and the R-S interval $20 \mathrm{sec}$. The UCS was a .5 sec shock at one of three intensities: Level 1 , $.75 \mathrm{~mA}$; Level 2, $1.50 \mathrm{~mA}$; Level $3,3.00 \mathrm{~mA}$, depending upon from which group the $S$ was chosen. All responses occurring during the $R-S$ interval were recorded at 1-min intervals by an automatic print-out. When the avoidance response was established and the operant levels had stabllized, the schedule was modified by the addition of free, unavoidable shock at $30-\mathrm{sec}$ intervals. This raised the operant level and guaranteed that each $S$ would receive the same minimum number of shocks. Training sessions were conducted for $8 \mathrm{~h}$ every other day until stable operant rates were established.

Ss were then introduced to the experimental situation and allowed a warmup period of $90 \mathrm{~min}$ at the UCS level on which they had been trained. Following this, the UCS level was randomly altered every $5 \mathrm{~min}$ among three UCS intensities: $.75 \mathrm{~mA}, 1.50 \mathrm{~mA}$, and $3.0 \mathrm{~mA}$. The response rate during the $\mathrm{R}-\mathrm{S}$ interval of each $5 \mathrm{~min}$ segment was recorded and used to calculate the net change in response rate between the 5 min segments. This change was calculated for nine conditions, all representing changes from one UCS intensity to another. To wit:

\begin{tabular}{rr} 
From & \multicolumn{1}{c}{ To } \\
$.75 \mathrm{~mA}$ & $3.00 \mathrm{~mA}$ \\
$1.50 \mathrm{~mA}$ & $3.00 \mathrm{~mA}$ \\
$.75 \mathrm{~mA}$ & $1.50 \mathrm{~mA}$ \\
$3.00 \mathrm{~mA}$ & $.75 \mathrm{~mA}$ \\
$3.00 \mathrm{~mA}$ & $1.50 \mathrm{~mA}$ \\
$1.50 \mathrm{~mA}$ & $.75 \mathrm{~mA}$
\end{tabular}

and three situations where the same UCS intensity level was presented in two successive 5-min segments. Resulis

Only the six situations listed were evaluated statistically. Here a two-way analysis of variance was employed to elucidate the effects on changes in performance of (1) the training level of the UCS and (2) the change in UCS intensity, plus interactions.

Significant differences in responding were found to result from changes in UCS intensity ( $F=44.46$, $p<.01)$. Figure 1 indicates their exact nature. Except for changing the shock intensity from $1.50 \mathrm{~mA}$ to $3.00 \mathrm{~mA}$ and vice versa, increasing shock intensity increased rate of responding while decreasing inten- 


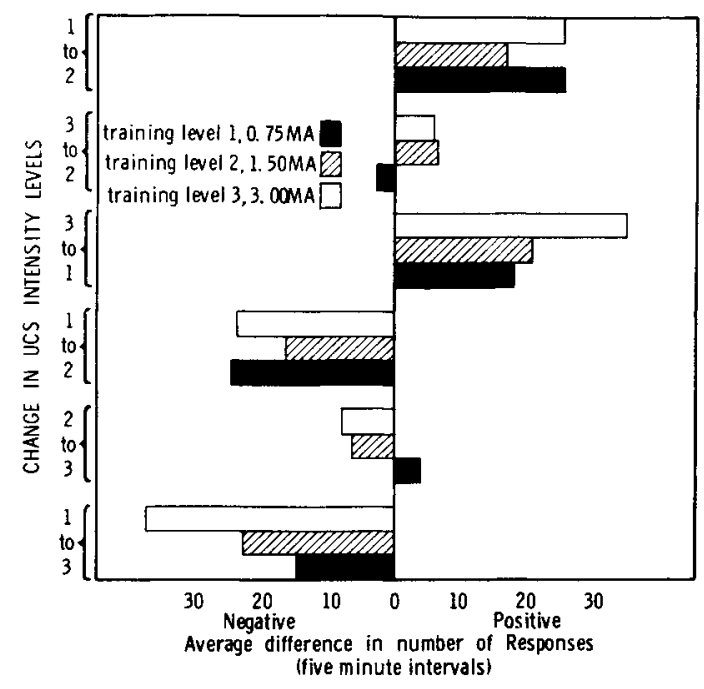

Fig. 1. Change in response rate as a function of Training Level of UCS and change in UCS Intensity Level.

sity decreased it. Furthermore, when the change in shock intensity was greatest, $i_{0}$.e, from $.75 \mathrm{~mA}$ to $3.00 \mathrm{~mA}$ and vice versa, it was obvious that how much, more or less, the response rate changed was due to training shock intensity (see Fig. 1). Responding was more affected in those Ss trained using a UCS of .75 mA and less in those using either 1.50 or $3.00 \mathrm{~mA}$. When the UCS change was not so great, i.e., when it varied from .75 to $1.50 \mathrm{~mA}$ and vice versa, the Ss whose responding was most affected were those trained on either the .75 or $3.00 \mathrm{~mA}$ intensities, i.e., again the most extreme values. These relationships were reflected in a significant interaction effect between training level and change in UCS intensity during performance $(F=28.25, p<.01)$. There were no significant main effects of UCS training level on the dependent variable used, changes in rate of responding; none were expected. All Ss failed to respond differentially to changes in intensities from 1.50 to $3.00 \mathrm{~mA}$.

Discussion

Clearly Ss were able to discriminate all changes in UCS intensity, except those from 3.00 to $1.50 \mathrm{~mA}$. Increasing UCS intensity increased avoidance responding, while decreasing it reduced responding. Furthermore, when the UCS intensity was either increased or decreased to the extreme, Ss responded differentially depending upon their training UCS intensity. Apparently, increasing shock produced increased aversiveness, while decreasing it resulted in decreased aversiveness. How aversive changes in shock intensity were depended upon (1) the UCS level just prior to a UCS change and (2) the Ss' UCS training level. There can be little doubt that the relationship between avoidance and shock is a relative rather than an absolute matter.

\section{References}

Bolles, R. C., \& Warren, J. A., Jr. The acquisition of bar press avoidance as a function of shock intensity. Psychon. Sci., 1965, $3,297-298$.

Hurwitz, H. M. B., \& Dillow, P. V. The effects of constant current shock intensities on the acquisition of a discriminated avoidance response. Psychon. Sci., 1966a, 5, 109-110.

Hurwitz, H. M. B., \& Dillow, P. V. The effects of constant power shock on the acquisition of a discriminated avoidance response. Psychon. Sci., 1966b, 5, 111-112.

Jerison, H. J. Patterns of extinction of a detection-indicating response under escape-avoidance reinforcement. Psychon. Sci., $1966,5,279-280$.

Levine, S. UCS intensity and avoidance learning. J. exp. Psychol., 1966, 71, 163-164.

Sidman, M. Avoidance behavior. In W. K. Honig (Ed.), Operant behavior: areas of research and application. New York: AppletonCentury-Crofts, 1966.

Note

1. This research was supported by the Research Council of the University of South Florida. 